\title{
JUDAÍSMO Y COMPROMISO SOCIOPOLÍTICO EN A. HESCHEL
}

\author{
Judaism and Sociopolitical Commitment in A. Heschel \\ Héctor Sevilla Godínez \\ Universidad de Guadalajara \\ hectorsevilla@hotmail.com
}

\begin{abstract}
Resumen:
El presente texto tiene como finalidad mostrar la convergencia entre ética, política y mística judía. Para ello, se parte de un conjunto de reflexiones aportadas por Abraham Heschel, un rabino y filósofo polaco que vivó durante el siglo XX. El artículo se encuentra dividido en cuatro partes, abordando en primer lugar el compromiso ético y político que se desprende de la filosofía de la religión propuesta por Heschel. Posteriormente, se alude al valor de la acción y la implicación de lo religioso con lo social, de lo místico con lo político. En un tercer momento se enfatiza el sentido del servicio, entendido como aportes individuales para la construcción del bien comunitario. Por último, la atención se dirige a la invitación de Heschel para la promoción de la justicia y serán aludidos diversos aspectos de su relación con Luther King.
\end{abstract}

Palabras clave:

Ética, Acción, Servicio, Justicia, Judaísmo

\begin{abstract}
:
The present text aims to show the convergence between ethics, politics and Jewish mysticism. To do this, it starts from a set of reflections contributed by Abraham Heschel, a Polish rabbi and philosopher who lived during the 20th century. The article is divided into four parts, first addressing the ethical and political commitment that emerges from the philosophy of religion proposed by Heschel. Subsequently, it alludes to the value of action and the involvement of the religious with the social, of the mystical with the political. In a third moment, the sense of service is emphasized, understood as individual contributions for the construction of community well-being. Finally, attention is directed to Heschel's invitation to promote justice and various aspects of his relationship with Luther King will be alluded to.
\end{abstract}

Keywords:

Ethics, Action, Service, Justice, Judaism

Recibido: 05/11/2020

Aceptado: 30/11/2020 


\section{Compromiso ético y político}

La vivencia de lo místico, la conformación de una espiritualidad concreta y la disposición al pathos divino no son suficientes si no se traslada toda la experiencia hacia el compromiso ético y político. Una religiosidad sin compromiso resultaba poco ecuánime para Heschel, quien consideraba que era menester manifestar con actos lo que uno afirmaba en su oración. En ese sentido, vivir de manera correcta no se sujeta en forma exclusiva a una cuestión abstracta, mucho menos a un estado de gozo continuo o de búsqueda unificada de sosiego y armonía. En mención de los judíos, el rabino, afirma: "Para nosotros el problema básico no es cuál es la acción correcta, ni cuál es la intención correcta. El problema básico es ¿qué es el vivir correcto?" (Heschel, 1984b: 379). Es evidente que tal planteamiento es de orden ético, ámbito que Heschel dominaba por haber sido profesor de Ética y Misticismo en el Seminario Teológico Judío de América.

Entendida como un ejercicio de reflexión en torno a la conducta apropiada en cada caso, la ética se distingue de la moral por no fundarse en un seguimiento sumiso del mandato establecido, sino por revisar con cautela, en razón del propio criterio, las circunstancias concretas en las que se presentan los dilemas. Por tanto, "la ética [...] espera que todo hombre reúna dentro de sí la capacidad de juzgar y la de ejecutar" (Heschel, 1982: 184). Si bien Abraham Joshua reconoció el valor de la vida, sabía que no basta con estar vivo para saber cómo vivir. En sus palabras, "tan sólo vivir es sagrado. Y sin embargo, estar con vida no es una respuesta a los problemas de la vida. Ser o no ser no es la cuestión. La cuestión vital es ¿cómo ser y cómo no ser?" (Heschel, 1987: 77). En la búsqueda por la norma del acto ético, el nacido en Varsovia pudo observar que la conexión del hombre con el pathos divino requiere de concreción para definir lo que corresponde hacer en cada momento. Se necesita disposición para captar los signos que se presentan alrededor; desear causar beneplácito en los demás no tendría que ser un criterio de nuestro proceder, de modo que "no podemos aceptar la aprobación social como una norma para lo bueno o lo malo, o para la autenticidad judía, porque el pueblo judío puede estar equivocado, así como cualquier individuo puede estar equivocado" (Heschel, 1987: 163).

Una de las manifestaciones específicas del compromiso ético y social es la disposición al trabajo, es decir, el prestarse a la realización de actividades que aporten un aliciente, un motivo o un beneficio particular a la sociedad; son notables, por ejemplo, las alusiones heschelianas al vínculo entre el ejercicio de los profesionales de la salud y la práctica de la espiritualidad, lo cual ha sido objeto de estudio (Barnard, 1985). En ese sentido, "la respuesta judía al problema de la civilización no es huir del reino del espacio; [es] trabajar con las cosas del espacio, y estar enamorado de la eternidad" (Heschel, 1984a: 229). Si Dios está presente en el tiempo, al hombre le corresponde manifestarlo con sus actos en el ámbito de lo espacial. Cuando el trabajo es realizado en vistas de la prosperidad comunitaria existirán consecuencias que, a corto o largo plazo, redundarán en resultados positivos. Las consecuencias oportunas de las buenas acciones no tienen una marca religiosa particular, de modo que "las buenas acciones de cualquier hombre, sea cual fuere la nación o la religión a la que pertenezca, aun cuando sean realizadas por una persona que jamás fue alcanzada por un profeta y que por lo tanto actúa sobre la base de su propia intuición, serán 
premiadas por Dios" (Heschel, 1984a: 379). No obstante, de esto no se desprende que los actos bondadosos deban tener como única finalidad el logro de un premio, puesto que proceder así desvirtuaría la ética y se volvería un planteamiento moral condicionado.

Cuando Heschel establece la noción del premio de Dios no se refiere a una representación teatral en la que uno exige su ganancia por el acto bondadoso, sino que éste reporta ganancias por sí mismo en la estructura del orden temporal. Por lo tanto, "uno ha de hacer siempre el bien, aunque no sea por el bien mismo" (Heschel, 1984a: 518). Lo que se hace de manera correcta fructifica en un bienestar concreto. Habrá ocasiones en que no sea claro el motivo por el que se realiza un acto o no se tenga un parámetro para valorar el beneficio directo que éste ocasione para la comunidad, pero "el buen motivo nace mientras se hace el bien" (Heschel, 1984a: 519). De cualquier manera, "el hombre no está al servicio de las buenas acciones; las buenas acciones están al servicio del hombre" (Heschel, 1984a: 397); visto así, lo hecho forjará armonía en algún punto concreto. No actuamos porque estemos programados para hacerlo, lo hacemos porque los actos son una mediación, no una finalidad. No hay bienestar sin conductas que lo aproximen.

Además, en la perspectiva hescheliana se establece que existe una particular presencia de Dios en los actos, de modo que "el acto es lo divino enmascarado. [...] Lo divino canta en nuestras buenas acciones, lo divino se manifiesta en nuestros actos sagrados" (Heschel, 1984a: 400). Puesto de esa manera, la manifestación de Dios en el tiempo es mayormente palpable cuando en el tiempo mismo se realiza un acto que lo hace presente. Es claro que para el judaísmo tiene más sentido creer en la inmanencia de Dios en los actos que en su presencia estática en la naturaleza. En esa perspectiva, el hombre es responsable de la materialización concreta de la presencia de Dios en el mundo. De ahí que "la relación entre acto y devoción interior no ha de entenderse como una polaridad" (Heschel, 1984a: 392). La comprensión de la alianza entre Dios y el humano no deja lugar a la tibieza ni a la exclusión de ninguna persona, pues todas ellas son una oportunidad para la concreción de acciones correctas.

\section{El valor de la acción}

De poco sirve el éxtasis espiritual si no hay trabajo de por medio, si la práctica es débil; en consonancia con ello, "las más puras intenciones, el más elevado sentido de devoción, las más nobles aspiraciones espirituales son fatuas cuando no se plasman en acción" (Heschel, 1984a: 434). El acto permite la visualización del grado de espiritualidad de un individuo. La colaboración social no nos implica una ajetreada vida pública, sino la orientación del talento hacia un legado que suponga un aporte. Incluso un artista, en la soledad de su acto creativo, propicia la concreción de su compromiso social al generar belleza apreciable o al invitar a la reflexión, tal como también puede hacerlo un filósofo o un investigador de cualquier área.

La conducta correcta debe hacerse por convicción, no porque constituya una regla o una obligación. En ese sentido, el filósofo de ascendencia jasídica establece que "la meta es vivir más allá de los dictados de la ley, cumplir lo eterno súbitamente, crear el bien a partir de la nada, por así decirlo" (Heschel, 1984a: 392). A la vez, son 
innecesarios los comparativos entre las conductas de unos y otros, como queriendo establecer quién ha generado mayor bondad; justo como acontece con el estudio, cada individuo debe realizarlo porque es su gusto y cualificación personal, no por necesidad de obtener aplausos o loas. En el ejercicio de la piedad judía, Heschel (1984a: 395) refiere un principio explícito en Berajot [Tratado de la Orden de Zaraim] (17a): "No importa que alguien haga mucho o poco, siempre que tenga el corazón dirigido al cielo". Incluso cuando se hace mucho, la intención tendrá que estar centrada en la ejecución del acto, tal como hace un creativo con aquello que crea: él es la creación mientras ésta surge. Del mismo modo, "en el momento en que un artista se halla absorbido en la ejecución de un concierto, la idea del aplauso, la fama o la remuneración se halla muy lejos de su mente. Su atención total, su ser entero están inmersos en la música. [...] No muy distinta es la situación del hombre cuando lleva a cabo una acción religiosa o moral" (Heschel, 1984a: 519). Mientras dormimos no solemos preguntarnos cómo nos vemos o de qué modo haremos saber a otros lo que estamos soñando, permanecemos conducidos por el sueño; de igual manera se espera el gusto y el libre fluir por lo que se hace en la vigilia.

La discusión ordinaria que dicotomiza el ser y el hacer no es necesaria cuando se logra la noción de que el ser se evidencia en el hacer. Aún más, "debemos aprender a ser uno con lo que hacemos" (Heschel, 1984a: 397). Esto no debe confundirse con la trivial fusión del ser y el hacer, puesto que "los actos son manifestaciones del ser, no su esencia" (Heschel, 1984a: 398), pero en el momento en que son realizados, los actos muestran lo que la persona ha logrado ser. Una similar correspondencia existe entre el culto y la conducta; el nivel del primero se muestra en el rigor de la segunda. Según lo reflexiona Heschel (1984a: 489), "a menos que nuestro vivir sea una forma de culto, nuestro culto no tiene vida". Esto significa que la fe tendría que ser clarificada en actos que se derivan de un auténtico compromiso ético y político. Desde este enfoque, "la fe desencarnada, la fe que procura crecer en esplendido aislamiento, es sólo un fantasma para el que no hay lugar en nuestro mundo psicofísico" (Heschel, 1982: 174). Así como la ciudadanía termina por hartarse de los políticos que sólo prometen y endulzan el oído con su retórica saturada de simpleza y vulgaridad, también tendría que manifestar su hastío hacia los religiosos que se proclaman herederos de una numinosidad extrema, pero que no emergen de su pasividad insensible.

No es suficiente con invertir demasiado tiempo a la oración o promover una mortificación centrada en sustraer algún bien o placer. "La oración no tiene sentido si no es subversiva, si no busca derribar y destruir las pirámides de insensibilidad, de odio, de oportunismo y de falsedades" (Heschel, 1987: 75); de esto se desprende la utilidad de la rebeldía, del coraje hacia la mediocridad, del desprecio de la injusticia. No hay forma de palpar el descontento si se mantiene la animosidad estable. Huir del mundo, del espacio terreno o del caos cotidiano que salpica las relaciones humanas y las instituciones sociales representa una conducta de salvaguarda que no tendría que prolongarse demasiado tiempo. Guardar distancia es útil cuando permite una nueva significación de las cosas y de los acontecimientos. Heschel (1987: 89) menciona que "no nos apartamos del mundo cuando rezamos; simplemente vemos al mundo en un marco diferente". Si la oración no combate la indiferencia, se convierte en solemne autocomplacencia. 
La responsabilidad ante la injusticia no es sólo de quien la comete, también le pertenece a quienes la permiten. El rabino polaco consideraba que "nuestras energías son demasiado abundantes para vivir con indiferencia" (Heschel, 1952: 117). Tenemos un tiempo limitado y transcurrimos en él sin darnos cuenta, no nos corresponde el desperdicio del talento ni de la fuerza. La modalidad de la existencia humana es corresponsabilidad de quienes conformamos su historia. Aquellos que se respaldan en obsoletas justificaciones para su apatía no han entendido que no es con otros con quienes deben explicar su tibieza, sino consigo mismos al final de su propio tiempo. En tal óptica, "si alegamos no tener corazón para sentir ni alma para oír, imploremos el don de las lágrimas o la vergüenza" (Heschel, 1982: 79). Estar dispuesto a dirigir la mirada hacia el otro exige comprensión de sus circunstancias; es ahí donde la pereza vence a las nobles intenciones. "Es sospechosamente más fácil sentirse uno con la naturaleza que sentirse uno con todos los hombres, con el salvaje, con el leproso, con el esclavo" (Heschel, 1982: 105).

Formar parte de un grupo social no tendría que obligarnos a estar de acuerdo con la incongruencia de los sistemas y las instituciones que conforman la participación de la ciudadanía. No se trata únicamente de adaptarse, "junto con la adaptación a la sociedad debemos cultivar la sensibilidad a la injusticia, la impaciencia con la vulgaridad, la capacidad para la indignación moral, la voluntad para readaptar [a] la sociedad misma cuando se torna complaciente y corrupta" (Heschel, 1987: 158). Cabe denostar la frialdad hacia la situación del país del que cada quien forme parte, entendiendo que la "indiferencia es insensibilidad" (Heschel, 1987: 295). Al juzgar a la sociedad no tendríamos que suponer que reposamos en un lago de perfección individual; es obligatoria también la autocrítica y facultarnos para la paciente disputa con nuestras incongruencias. Es por esto que "no estamos obligados a ser perfectos de una vez para siempre, sino a elevarnos una y otra vez por encima del nivel del yo. [...] La contrición comienza con un sentimiento de vergüenza por nuestra incapacidad para desenredarnos del ego. Estar contritos por nuestras faltas es más santo que complacernos en la perfección" (Heschel, 1984a: 515). Lo humano está constantemente puesto a prueba, puesto que el laberinto de lo que somos y lo que creemos ser arroja una loza de confusión de la que solemos resguardarnos con alguna compensación.

Si bien "la preocupación por los demás no es una extensión horizontal sino una ascensión, una elevación" (Heschel, 1982: 139), incluso al servir a otros podemos desatender las propias fallas; la atención a la comunidad no tendría que ser el maquillaje del desinterés hacia el proceso personal. En ese tenor, resulta fundamental mantener la atención en forma tridimensional; en concreto, "el yo, el prójimo y la dimensión de lo sagrado son las tres dimensiones de una preocupación humana madura" (Heschel, 1982: 139). Mantener la mirada en el yo deviene en vanidad que no se compromete; forjar una comedida centralización en el otro termina por hacernos olvidar el autocuidado; sustraer todo servicio comunitario y olvidar las propias necesidades no es indicativo de que nuestra perspectiva de lo sagrado sea rigurosa. 


\section{Sentido del servicio}

Cuando se alimenta la noción de que estamos en el mundo por derivación de una serie de circunstancias que, incluso siendo un azar, suponen una increíble coincidencia de circunstancias favorables, se forja el sentido de deuda personal hacia lo externo. Tomamos oxígeno y alimento del ambiente, así como hemos sido beneficiados por una larga serie de favores y atenciones que otros nos han facilitado, conociéndonos o sin saber quiénes podríamos llegar a ser. No hay gratuidad en la existencia humana, de modo que nos corresponde un sentimiento de deuda hacia lo que nos rodea. Por el contrario, "el hombre moderno cree que el mundo está en deuda con él, que la sociedad está cargada de deberes para con él" (Heschel, 1987: 151), por lo que se centra en lo que puede obtener y no en lo que es capaz de ofrecer, anulando así su compromiso ético y político.

Al no concebir necesidad alguna de ofrecer lo que se tiene, no es posible elevar el sentido de la utilidad personal. Quien se acostumbra sólo a recibir termina por creer que no es capaz de ofrecer algo valioso. No obstante, el hombre y la mujer necesitan sentirse necesarios, requieren de la percepción de su utilidad social. Si "una persona es aquello a lo cual aspira" (Heschel, 1982: 261), resulta fundamental que la aspiración sea alta y concreta. Sin embargo, cuando la aspiración es servirse de los demás, lo que se muestra de uno mismo es compatible con la miseria de nuestro ofrecimiento. Vivimos en una especie de nube espesa que confunde nuestro criterio; de tal aturdimiento se propicia que se alabe al que tiene más y no al que más ofrece, que se tome como modelo de vida y conducta la de aquel que manipula y utiliza a las personas, no la de quien hace de ellas un motivo de sus actos. No se trata de elegir el servicio y terminar siendo utilizado por algún alevoso ventajista, se trata de agudizar el criterio para servir sin convertirse en sumiso, ofrecer lo que se tiene sin perder los propios satisfactores, dar sin convertirse en un ingenuo esclavo de las pretensiones ajenas. Por eso, no cabe dar lo que no es necesario, ni será oportuno ofrecer lo que el otro puede hacer por sí mismo. Cuando se es necesario se logra el complemento de otro, no su sustracción. Heschel (1982: 260) destaca que "la felicidad no es sinónimo de satisfacción, complacencia o presunción, sino, esencialmente, la certeza de ser necesario, la visión de la meta que aún queda por alcanzar". Nadie debería revelar de forma anticipada lo que al otro le corresponde descubrir, pero sí puede ofrecerse un aliciente para tal descubrimiento.

La conducta humana está sujeta, cuando es elegida, a la expectativa que se tenga en cada caso particular, a la cosmovisión; de tal modo, "lo que el hombre piensa de sí mismo, de su pueblo, de la humanidad, determina su manera de tomar decisiones" (Heschel, 1987: 190). Por ello es oportuno considerar nuestra propia idea sobre el bien que sustancia a la bondad y los bienes materiales que corresponden al mundo físico. Desde el punto de vista judío, el bien no puede asociarse con la eliminación de algo o con la sustracción de un valor. Por ejemplo, "la mera pobreza como tal no es un camino, pues la amargura de la miseria suele alterar el equilibrio de valores del carácter humano, mientras que el deleite que encuentra el hombre virtuoso en los regalos de Dios le otorga la fuerza para servir y los medios para dar" (Heschel, 1982: 294). No es inteligente negar las facultades del dinero, ni argumentar contra él como si fuese el enemigo al vencer; lo que corresponde, en todo caso, es facultar una 
voluntad y un criterio tal que haga del recurso económico un instrumento para el servicio y la fabricación de oportunidades que apunten al desarrollo de las personas. No se trata de elegir la pobreza o de exaltar la miseria que nos conduce a vivir de la limosna de los demás, como hacían en su tiempo los mendicantes, sino que la promoción del cambio y la prosperidad espiritual será favorecida si se sostiene en una plataforma material básica. Si la abundancia promueve la caridad, es mejor que sea ésta la que florezca en vez de una mendiguez que sólo amontona lástima.

Lo mismo podría aplicarse en el terreno de los conocimientos y la sabiduría: la acumulación puede ser oportuna si se canaliza en forma funcional y se aprovecha para generar nuevos conocimientos o reflexiones en los demás. De poco sirve la supuesta humildad del que antepone su sencillez para justificar su pereza por aprender. Asimismo, en lo tocante al deleite proveniente de los bienes el cuerpo, "en ningún lugar de la Biblia hay indicio alguno que apunte a la idea de que el alma está prisionera en un cuerpo corrupto; que buscar satisfacción en este mundo significa perder la propia alma o violar el pacto celebrado con Dios; que la obediencia a Dios exige la renuncia a los bienes terrenales" (Heschel, 1982: 266). No se es más sagrado en proporción a la castidad, cuando ésta lo único que logra es perpetuar el deseo desenfrenado; mejor virtud existe en el ofrecimiento del goce carnal que en su privación y trastorno. Visto así, "hasta la gratificación de necesidades animales puede ser un acto de santificación" (Heschel, 1982: 269). Tal como el inadecuado uso de la riqueza o la egoísta acumulación del saber, el placer desmedido y poco precavido o selectivo también podría resultar perjudicial.

Del gusto por compartir deviene la exclusión de la vanidad. En la óptica hescheliana "el hombre piadoso no espera recompensas. Aborrece la exhibición, la exterioridad que busca llamar la atención en cualquier forma, y evita tímidamente exponer sus cualidades incluso ante su propia mente" (Heschel, 1982: 281). De modo que, si hemos logrado escapar del egoísmo ante nuestras riquezas, aún nos corresponde evitar la vanidad que podría derivarse de hacer pública la manera en que compartimos lo que tenemos. Por otro lado, también en los casos en que se opta por la pobreza existe el latente peligro de la autocomplacencia en el supuesto desapego a la abundancia. Con esto se muestra que la vida religiosa es algo más que la simple apuesta por la pobreza, la obediencia y la castidad. Si en vez de ello se hicieran votos para asegurar el aprovechamiento honorable de la riqueza, el ejercicio ético personal y la glorificación de Dios por mediación del gozo, podríamos establecer un ámbito de mayor apertura y aceptación de lo humano. En un contexto así se vuelve fundamental la capacidad de discernimiento. Heschel (1982: 271) propone que "cuando uno cobra conciencia de una necesidad, debe preguntarse: ¿me acompaña Dios en mi necesidad?" Por tanto, no se está recomendando la libertina opción de someter la existencia al instinto, sino que se invita al resurgimiento de la responsabilidad personal.

Ni todo deseo debe ser rechazado, ni cada interés satisfecho. Esto no significa que la autoinspección sea lo mismo que la sumisión. Tal como afirma el filósofo judío, "sólo los hombres libres, los que no son proclives a canonizar cada capricho, no equiparan el autocontrol con sometimiento, ya que saben que ningún hombre es libre si no es dueño de sí mismo, que cuantas más son las libertades de las que gozamos, 
tanto mayor es la disciplina que necesitamos" (Heschel, 1982: 273). Cuando en algunas religiones se obliga a las personas a seguir un definido patrón de conductas no se está confiando en el criterio de los feligreses ni se está respetando su eventual capacidad de disciplinarse.

\section{La búsqueda de la justicia}

No hay opción ética congruente que no desemboque en la participación política. Cuando hablamos de ser políticos no apuntamos a la militancia en algún partido o a la pretensión de gobernar, sino a la injerencia en las situaciones propias de la polis. Heschel, como "hombre de diálogo" (Gottschalk, 1973), afirmó: "Estoy en contra de la palabra político. Tengo gran estima por la palabra estadista" (Heschel, 1987: 355). El término supone otro nivel de ejercicio político, no sólo el intrínseco que corresponde a toda persona. Heschel (1987: 356) especifica que "la tarea de un estadista es ser un líder, un educador, y no complacer los deseos del pueblo en contra de sus propios intereses". Por lo tanto, una manifestación del posicionamiento político de un individuo también puede ser observada en su diligencia por mostrarse como un referente educativo o como un promotor de la reflexión.

Es sabido que algunas posturas religiosas recomiendan el alejamiento de la política y proponen no inmiscuirse en ella. No obstante, "si se leen las palabras de Dios en la Biblia, se ve que se inmiscuía en asuntos políticos y sociales" (Heschel, 1974: 34). En el prólogo a la trilogía de Los Profetas, Meyer (1973: 10) refiere la escritura de ese libro como una muestra de participación política que puso en evidencia la carencia de líderes capaces de cultivar la lealtad del hombre contemporáneo. De tal manera, incluso la labor de un escritor constituye una muestra de su involucramiento político, según sea el contenido de sus textos, sobre todo en tiempos en que su voz confronta los dictados de los supuestos líderes mediáticos que son sólo productos de la infraestructura de las telecomunicaciones.

Sobre la virtud del involucramiento político, Heschel (1987: 348) reitera: "Hay quienes dicen que el líder religioso no debe participar en política, [...] yo diría que Dios parece ser una persona arreligiosa, porque si leemos las palabras de Dios en la Biblia, veremos que siempre se inmiscuye en política y en problemas sociales". A pesar de ello, el rabino polaco cuestionó la validez de su propia intervención en algunas situaciones problemáticas de su tiempo. De acuerdo con Bizzell (2006:11):

Heschel no podía estar seguro de que no sería ofensivo que siendo un blanco hablara en nombre de los derechos civiles de los negros y que como judío ofreciera una dirección teológica a los cristianos. Pero él sentía que las cuestiones en juego eran lo suficientemente graves como para que él elevara su voz si, de cualquier modo, pudiera promover la causa de la justicia, incluso a pesar de que su comportamiento fuera cuestionable. Por temor a ofender a alguien, muchas personas se silencian hoy en día.

La denuncia, más que el silencio cómplice, es indicativo de una rebeldía virtuosa. En uno de los textos escritos por su hija Susana (1990), ella recuerda cómo su padre se sintió complacido cuando desafió a su familia y a sus maestros confrontando los 
impedimentos para que una mujer estudie la Torah. En consonancia con los postulados del rabino polaco, algunas mujeres han sido aceptadas recientemente para realizar los estudios rabínicos. Fuera del ámbito religioso, Heschel consideraba que "hablar sobre Dios y permanecer en silencio sobre Vietnam es blasfemo" (Heschel, S. 1996: 231); del mismo modo sucede en la actualidad cuando excluimos de nuestra conversación el problema económico y la corrupción de los sistemas políticos de varias naciones, la discriminación en todas sus modalidades, la falacidad de algunos sistemas educativos, la hegemonía de algunos monopolios o la interminable disputa en Palestina. Por todo ello, Kaplan (1987: 22) concuerda en que "aquellos que no se emocionan con la evidencia diaria de conflictos armados, muerte, opresión social y económica, o niegan la mediocridad de las instituciones religiosas contemporáneas, tendrán dificultad en entender los patrones religiosos de Heschel". Cada historia y grupo social presenta retos y sensibles oportunidades para ejercer la capacidad crítica y mantener una firme rebeldía ante el control mediático o ante la fría trivialidad implícita en las condiciones habituales de la vida social.

Estar atento al pathos divino, a la emocionalidad de Dios, implica una impostergable e irrenunciable búsqueda de justicia. En el vínculo entre Dios y el hombre se fortalece la noción de la justicia que corresponde implementar en el mundo. De tal manera, "la justicia no es una costumbre antigua, una convención humana, un valor, sino una exigencia trascendente, plena de interés divino" (Heschel, 1973: 75). En uno de sus libros, Rothschild (1976) hace mención de la particular interpretación del judaísmo realizada por Heschel, centrada en la idea de que el hombre necesita ser necesitado por Dios en la hora presente de cada instante. Así, de manera inversa a lo que se piensa, la justicia tendría que ser el modo original de las cosas; en un estado en el que no existiese distorsión, la justicia imperaría. Aquel a quien Al-Yahud (1952) Ilamó "pensador creativo" alude que "la gente piensa que ser justo es una virtud que merece honores y recompensas; que al hacer justicia se confiere un favor a la sociedad. Nadie espera recibir una recompensa por el hábito de respirar. La justicia es tan necesaria como la respiración, y una ocupación constante" (Heschel, 1973: 76). Se observa entonces que la justicia no es un lujo del que pueda prescindirse, es una obligación para la auténtica humanidad en cada espacio y lugar del mundo.

Uno de los pasajes bíblicos más reiterados por Heschel es el que está incluido en el libro de Amós (5, 24), que citado por Heschel (1973: 99) dice: "Deja que el juicio corra como las aguas, y la justicia como una poderosa corriente"; lo que el rabino interpreta de esta frase es que la justicia tendría que ser el orden del mundo y de las relaciones humanas. Para él, Amos se refiere a "una corriente poderosa que expresa la vehemencia de un movimiento interminable, emergente, luchador, como si hubiera que barrer los obstáculos para dar paso a la justicia" (Heschel, 1973: 99). Promover la educación es una manera previsora de evitar la injusticia, pues un pueblo educado será más difícil de someter y de conducir a la sumisión. La búsqueda de mejores condiciones de vida muestra una formación versada en los conocimientos y en la estima personal. Por ello, la lucha contra la ignorancia y la opresión son un baluarte de la incansable pugna por la justicia. 
En relación a la manera en que los pueblos se dejan someter por la tiranía, Heschel hizo mención a la incongruencia de la ciudadanía, que lejos de exigir con seguridad lo que le corresponde, se contenta con mantener la vida a pesar de los abusos, como si el hecho de sobrevivir fuese suficiente para dotar de humanidad a una existencia. El profesor de Ética señala que "la ironía amarga de la historia es que el pueblo común, que no tiene poder y que es la víctima en potencia de su abuso, es el primero en aliarse con quien acumula el poder" (Heschel, 1973: 10). En el artículo donde Friedman (1973) refiere a Heschel como uno de los filósofos contemporáneos más importantes, también se advierte que no basta con persuadirse de estar vinculado con la emocionalidad de Dios, sino que es necesaria la acción profética. Con presteza puede decirse que la idea de Dios en el judaísmo lo asocia con el acontecer humano.

La urgente mirada al pueblo sufriente corresponde más a la voluntad divina que la alcurnia perfumada en las asambleas religiosas. La consideración del dolor y el hambre de los menos favorecidos es un acto más sagrado que lavar el cuerpo con aceites benditos. Por ello, Pérez (2007: 65) advierte que "el Dios de los profetas está más preocupado por los problemas humanos, por la justicia y la equidad, por los problemas de la política y del mercado, que por las cuestiones del culto. Esto, a la postre, impugnó fundamentalmente la aislada vida intelectual de Heschel y lo impulsó a comprometerse a fondo con los problemas sociales, al grado de que bien se le podría considerar un precursor de la Teología de la Liberación latinoamericana". Lo anterior posiciona a Heschel en un escalón distinto al de los grandes místicos que han agotado su labor en una celda o que no se han permitido llorar de rabia ante la desgracia de quienes los rodean. De hecho, Stampfer (1985) considera que la oración y el ejercicio político son los pilares de la espiritualidad hescheliana.

Una auténtica lucha por la justicia no puede desentenderse de estar en contra del racismo. Sin duda alguna, el racismo es producto de un modo de idolatría, de un culto a la vanidad o a la idea de superioridad de unos sobre otros. "Pocos de nosotros comprenden que el racismo es la amenaza más grave del hombre contra e1 hombre, el máximo de odio por un mínimo de razón, el máximo de crueldad por un mínimo de razonamiento" (Heschel, 1964: 34). Estamos rodeados de actos de crueldad que intentan ser justificados cruentamente por argumentos de supremacía que no son más que infantiles ficciones desarticulables. Heschel (1964: 35) no estaba de acuerdo con el menosprecio a las personas por el color de su piel. En concreto denunció que "este no es un mundo del y para el hombre blanco. Es el mundo de Dios. En este mundo no hay cabida para ningún hombre que intente subyugar a otro. Es tiempo que el hombre blanco se arrepienta". Con esto, el rabino se dirigía a los que tenían en el rostro el mismo color que él, pero no se detuvo ante la posible crítica de la que sería objeto; siempre se mantuvo como un sujeto valiente: su pertenencia a los grupos no lo convirtió en un peón de los mismos.

Uno de los vínculos más significativos en la vida de Heschel fue su amistad con Martin Luther King. La hija del rabino refirió que las afinidades entres ellos "emergen en el lenguaje que usaron para explicar sus posiciones políticas, pero aún más inesperadamente en el estado de ánimo religioso que evocaron a través de su lenguaje religioso" (Heschel, S., 1998: 128). En el análisis realizado por la misma autora existen al menos tres convergencias entre Heschel y King: a) una clara coincidencia en las 
formas de comprender la espiritualidad, considerando la notoriedad que King otorgó a la Biblia hebrea, sobre todo al Éxodo, así como la asociación entre profecía y liberación, a la que tanto recurría Heschel; b) el movimiento inspirado por King se mantuvo en franca reiteración de la preocupación divina por la justicia, justificando así la rectitud de la lucha por el respeto a los Derechos Civiles; c) las locuciones de King están precedidas de su propia certeza de haber sido enviado por Dios, por lo cual no intercede como un observador alejado de las circunstancias, sino que hizo de su lucha el motivo y compromiso de su vida; d) los actos y la conducta de King son coincidentes con la expuesta por Heschel cuando se refería a los profetas. Al igual que el rabino polaco, King recibió formación religiosa; en el caso del segundo, se preparó para su ministerio en el Crozer Theological Seminary; además, ambos contaban con un doctorado. Con esto se concuerda en la armoniosa ponderación de espiritualidad, racionalidad y compromiso social.

En el mismo texto, Susannah Heschel (1998: 131) alude que en los casos en que King utiliza el versículo de Amos $(5,24)$, con el que también se identificaba Abraham Joshua en su lucha por la justicia, hace uso de la traducción que éste último realizó para el libro de Los profetas, dejando a un lado la que se presenta en las versiones bíblicas que son utilizadas de manera usual por los teólogos cristianos. La traducción a la que hace referencia la hija de Heschel es la siguiente: "Que el juicio se derrame como las aguas, y la justicia como un poderoso arroyo" (Heschel, 1962: 212). Con esto es observable que su mutua comprensión del mensaje profético, así como la forma en que lo ligaron con su compromiso ético y político orientó a ambos hombres a luchar en contra de las injusticias. De ahí se sigue que "tanto Heschel como King hablaron el uno del otro como profetas" (Heschel, S., 1998: 140).

En uno de sus discursos, King (1986: 657-679) expresó con claridad el aprecio que tenía al teólogo de Varsovia. Una de las frases del discurso referido es citada por Susannah Heschel (1998: 140) en uno de sus libros: "Siento que el rabino Heschel es una de las personas que es relevante en todo momento, siempre con ideas proféticas para guiarnos a través de estos días difíciles". Por su parte, Abraham Joshua menciona enfáticamente la labor especial que realizaba su compañero de batallas: “¿Dónde en América oímos una voz como la voz de los profetas de Israel? Martin Luther King es una señal de que Dios no ha abandonado los Estados Unidos de América. Dios lo ha enviado a nosotros. Su presencia es la esperanza de América. Su misión es sagrada, su liderazgo de suprema importancia para cada uno de nosotros" (Heschel, 1968: 1). Ambos tenían claridad sobre la importancia de su amistad, no sólo en lo tocante al crecimiento e intercambio fructífero de sus ideas, sino en cuanto al mensaje que daban a la humanidad; su unión representaba la posibilidad de conjuntar la energía de judíos y cristianos, de blancos y negros.

En palabras de Kasimow (2009: 58), tanto Heschel como King "comparten el deseo de provocar una transformación espiritual radical de la humanidad. El problema central para ellos no es la supervivencia de la religión sino la supervivencia de los seres humanos. Heschel afirma que lo que se necesita es una revolución espiritual. Del mismo modo, en sus discursos, King llamó a una revolución en los valores". La trascendencia de la institucionalidad religiosa para dar paso a lo esencial de lo humano es evidencia de una clara opción por lo transpersonal que habita en cada ser. 
Si bien Kasimow (2009: 58) expresa que Heschel y King "nunca abandonaron la idea de que la religión es la forma de sanar al mundo, de que la religión puede ser una forma de lograr la paz", esto no incluye la intención de que una religión en concreto sea la portavoz de todos los hombres, sino que la esencialidad de cada religión, cuando ésta es honesta y centrada en lo transpersonal, puede hacer coincidir a los hombres entre sí y hacerlos trabajar juntos sin importar su credo.

La fotografía de Heschel caminando con los brazos entrelazados junto con King durante la manifestación en Selma se ha convertido, desde 1965, en un símbolo de la fraternidad interreligiosa y del entendimiento humano por encima de las diferencias religiosas. A pesar de que han pasado más de cincuenta años, "ninguna de las dos comunidades [judaísmo y protestantismo] tiene voces de liderazgo moral comparable a las voces de King y Heschel. El ánimo profético que crearon ha sido reemplazado por voces de testigos que hablan del racismo y el antisemitismo de nuestra sociedad, pero sin ofrecer la visión religiosa trascendente que ellos proporcionaron" (Heschel, S., 1998: 141). Así como lograron reunirse para apoyarse, "Heschel y King encontraron que la religión no siempre ha sido una fuerza para la libertad, la justicia y la paz" (Kasimow, 2009: 58); por esto, alentaron a que las divergencias de credo no convirtieran a las personas en enemigas, sino que fuesen una oportunidad para aprender del fervor y de la entrega de cada religioso. Tal como se ha dicho en esta obra, incluso los que no forman parte de ninguna institución religiosa pueden adoptar los elementos primordiales que muestran el brillo de lo humano en las manifestaciones religiosas. Es muy probable que aun en el caso de que no existiese ninguna religión el lazo humano con lo transpersonal se mostraría de muy diversas maneras, tal como sucede en los que no tienen ningún credo o filiación alguna.

El compromiso político de Heschel también quedó manifiesto en otras luchas y causas. Tal como lo menciona Levenson (1999: 23), "su nombre es constantemente invocado a favor de un gran espectro de causas contemporáneas, que van desde el pluralismo religioso hasta el feminismo y el medio ambiente". Asimismo, en sociedad con Richard Neuhaus y John Bennett, Heschel fundó en 1965 una organización antibélica que recibió el nombre de Clergy and Laymen Concerned About Vietnam [EI Clero y los laicos preocupados por Vietnam]. Como es natural, su militancia y su disposición para defender la justicia lo hicieron oportuno para las críticas y el surgimiento de varios detractores, según lo describió Tanenzapf (1974).

En virtud de su labor como pacifista, Heschel "nos enseñó a conjugar la metafísica con el activismo político" (Kullock, 2014: 1), lo cual no siempre sucede. La unión con otras personas no requiere del olvido de las propias creencias o convicciones, pero sí exige la prudencia y la calma para apreciar que las diferencias son oportunas porque establecen la pauta de los procesos de cada persona, así como la esencia de la tradición particular. Si la justicia en el mundo es una labor que corresponde a los humanos, es tiempo de favorecer que fluya y dejar de obstruirla, el río de la rectitud tendrá que forjar el rostro de un mundo que no pierde la esperanza. La espiritualidad no es contraparte de la ética, así como el compromiso político no es ajeno a la mística; corresponde a cada conciencia elaborar su juicio sobre la implicación de estas nociones y la añoranza que de ello se rescate. 


\section{Conclusiones}

La pregunta central de la ética trata sobre cómo vivir correctamente. La reflexión sobre lo que corresponde hacer no puede eludir el trabajo que corresponde a cada persona en la construcción de un mundo mejor. Las buenas acciones son entendidas como propiciadoras del progreso social, de modo que no es suficiente esperar un premio por realizarlas, sino comprender la presencia de un halo de numinosidad en los actos. Esto no supone que no sea el hombre responsable ante lo que hace, significa que tiene una convicción por encima de la regla y que es capaz de vincular su ser y hacer, su culto y conducta. Superar la indiferencia abre paso a la solidaridad, la cual se vuelve entrañable cuando alberga un sentido de deuda personal hacia el mundo y el universo; de tal perspectiva se desprende la noción de la utilidad personal que uno mismo puede generar.

El valor del bien y de los bienes se rescata cuando su abundancia se utiliza en favor de los desprotegidos, no a partir de la sustracción. Además, la exclusión de la vanidad por mediación del autocontrol favorece el nacimiento de un claro sentido político que deviene en solidaridad. Cuando el hombre y la mujer contemporáneos se comprometen socialmente manifiestan una rebeldía virtuosa ante la injusticia, de modo que se muestran dispuestos a luchar contra la ignorancia, la opresión y el racismo. Motivaciones similares generaron el vínculo de Heschel con Luther King, así como su involucramiento en otras causas políticas. Heschel entendió que la oración sin acción es estéril y que la mística no puede estar desprovista de sensibilidad ante la injusticia.

Ayer como hoy, la comprensión de lo que nos une y el fomento por el bienestar de cada individuo serán el punto de convergencia que hará coincidir las intenciones y permitirá la materialización de la utopía en la que el mundo sea un sitio digno para el humano y éste sea un ser apto para conectar con el espíritu reinante que se manifiesta en el tiempo.

\section{Bibliografía}

Al-Yahud, D. (1952). Professor Heschel, the Creative Thinker. The Jewish Forum, 35 (8), 137-141.

Barnard, D. (1985). Religion and Medicine: A Meditation on Lines by A. J. Heschel. Soundings, 68 (4), 443-465.

Bizzell, P. (2006). Rabbi Abraham Joshua Heschel: Religion and race. Voices of democracy, 1, 1-14.

Friedman, M. (1973). Abraham Heschel among Contemporary Philosophers: From Divine Pathos to Prophetic Action. Philosophy Today, 18 (4), 293-305. 
Gottschalk, A. (1973). Abraham, Joshua Heschel: A Man of Dialogue. Conservative Judaism, 28 (1), 23-26.

Heschel, A. (1952). La Tierra es del Señor. Buenos Aires: Candelabro.

Heschel, A. (1962). The Prophets (2 vols.). New York: Harper and Row.

Heschel, A. (1964). La base religiosa de la igualdad de las razas. Maj'Shavot/Pensamientos, 3 (2), 33-36.

Heschel, A. (1968). Conversation with Martin Luther King. Conservative Judaism, 22 (3), 1-19.

Heschel, A. (1973). Los profetas (vol. 2: Concepciones históricas y teológicas). Buenos Aires: Paidós.

Heschel, A. (1974). "Conversación con Heschel" [Entrevista realizada por Carl Stern]. Maj'shavot/Pensamientos, 13 (1), 33-39.

Heschel, A. (1982). El hombre no está solo. Buenos Aires: Seminario Rabínico Latinoamericano.

Heschel, A. (1984a). El Shabat: su sentido para el hombre moderno. Buenos Aires: Seminario Rabínico Latinoamericano, 1984.

Heschel, A. (1984b). Dios en busca del hombre. Buenos Aires: Seminario Rabínico Latinoamericano.

Heschel, A. (1987). Democracia y otros ensayos. Buenos Aires: Seminario Rabínico Latinoamericano.

Heschel, S. (1990). Heschel as Mensch: Testimony of his Daughter. En J. Neusner y N. Neusner (Eds.) (1990). To Grow in Wisdom: An Anthology of Abraham Joshua Hesche/(195-211). Lanham (Maryland): Madison Books.

Heschel, S. (1996). (ed.), Moral Grandeur and Spiritual Audacity. New York: Farrar, Straus, Giroux.

Heschel S. (1998). Theological affinities in the writings of Abraham Joshua Heschel and Martin Luther King, Jr. Conservative Judaism, 50 (2-3), 126-143.

Kaplan, E. (1987). Misticismo y desesperanza en el pensamiento religioso de A. J. Heschel. Maj’shavot/Pensamientos, 26 (12), 22-36.

Kasimow, H. (2009). Prophetic voices. Abraham Joshua Heschel's friendship with Martin Luther King, Jr. Interreligious Insight, 7 (2), 56-64. 
King, M. L. (1986). The Essential Writings and Speeches of Martin Luther King, Jr. San Francisco: Harper Collins.

Kullock, J. (2014). El D’s del Pathos en A. J. Heschel. Maj'Shavot / Pensamientos, 53 (1), 1-16

Levenson, J. (1999). The Contradictions of A. J. Heschel. Maj'shavot / Pensamientos, 37 (1), 23-29.

Meyer, M. (1973). Prólogo. En A. Heschel, Los profetas, vol. 1 (pp. 9-15). Buenos Aires: Paidós.

Pérez, V. (2007). La religión judía desde Buber y Heschel ante la posmodernidad. Historia y Grafía, 28, 41-68.

Rothschild, F. (1976). Between God and Man: An Interpretation of Judaism from the Writings of Abraham J. Heschel. New York: The Free Press.

Stampfer, J. (1985). Prayer and Politics, the Twin Poles of Abraham Joshua Heschel. Portland: Institute of Judaic Studies.

Tanenzapf, S. (1974). Abraham Heschel and his Critics. Judaism, 23 (3), 276-286.

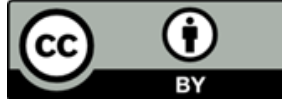

